guidelines for community services to be in place before discharge and recent well publicised fallures in community care, consultants are understandably taking fewer risks and are delaying discharge. Unfortunately this has had a 'knock on effect' for junior doctors assessing patients in accident and emergency departments. Often one is aware that there are no vacant beds on the psychiatry wards and admission could only be effected by using 'leave beds' or trying to use beds in other hospitals. Faced with this situation, the threshold for admission rises and increasing risks are taken. Thus the responsibility for taking risky decisions has been shifted from a consultant psychiatrist on the ward to a junior doctor in casualty.

Surely this trend is not the way forward.

FRANCES FOSTER, Fazakerley Hospital, Lower Lane, Liverpool

\section{Job-sharing a consultant post}

Sir: As a consultant psychiatrist imminently expecting the arrival of a fourth baby, I found the article by Black \& Callender on job-sharing a consultant post (Psychiatric Bulletin, January $1994,18,47-48$ ) very helpful and encouraging.

In 1991 the Department of Health became the first government department to join Opportunity 2000 in an effort to increase women's participation in the NHS. One of the stated goals was to increase the percentage of women consultants to 20 by the end of this year. Sadly there seems to be no prospect of achieving this and I believe that the prospects will remain bleak while colleagues continue to view new ways of working such as job-sharing with a high index of suspicion.

The Royal College of Psychiatrists under the presidency of Dr Fiona Caldicott has been extremely encouraging in this area, and I understand that a College Adviser on flexdble training and flexdble working is shortly to be appointed. However unless the College exerts strong leadership and continues to send out regular signals on this topic, it is my impression that there will continue to be subtle opposition to job-sharing and fair part-time work with all the resultant wastage of skills and resources that this implies.

ANNe CRemona, Wexham Park Hospital, Slough, Berkshire

\section{The dangers of the 'internal market'}

Sir: In parallel with the development of the NHS purchaser/provider split, an alternative 'internal market' has emerged in many hospitals - the phenomenon of the hospital lobby market stall usually selling such health-care necessities as cut-glassware, handbags, compact discs, jewellery and training shoes. Informal questioning reveals that these stalls 'generate income' for the hospital in the form of site fees paid by the stallholder.

Recently, a stall was set up in the main lobby of this hospital, selling 'discount cutlery'. Closer inspection revealed an assortment of carving knives and breadknives openly laid out for inspection. Three wards, accommodating up to $\mathbf{7 5}$ acutely ill psychiatric patients, are situated in the same bullding. On that day, as is usually the case, the wards contained a number of patients at risk of self-harm and several with a history of dangerousness to others and risk of further dangerousness.

Alan Lillywhite (Psychiatric Bulletin, February 1994, 18, 113) recently highlighted the assault potential of sharp metal letter-openers offered by drug company representatives. This example focuses attention on the dangers of giving planning responsibility for such income generation schemes to staff who have neither the clinical training, experience nor common sense to make decisions which ultimately affect the safety of staff, visitors and patients. The risks of bypassing clinical input are clear when designing such ventures.

ROBIN IRELAND, Newtown Branch, Worcester Royal Infirmary, Worcester

\section{Health care in Kerala}

Sir: We read with interest the foreign report by $R$. and L. Hackett (Psychiatric Bulletin, 1993, 17, 752-754) which regrettably fails to give a comprehensive picture and is riddled with dangerous generalisations and distortion of facts.

Kerala is one of the most densely populated. culturally mixed and politically unusual states in the world. About the size of Switzerland, it has a population of 30 million people, $60 \%$ are Hindus, 20\% each Muslims and Christians. Midway along the spice route between Rome and China. Kerala thrived as an international meeting place from the lst century $A D$ so becoming the first destination in India for Christians, Jews and Muslims, whose descendants have added a cosmopolitan flavour to this enlightened Hindu state.

However, Kerala is now known for different reasons. In 1957 it voted a Communist government to power, the first in history. More recently, its success has received wide attention, "it is a poor state in a poor country which manages to keep its people alive longer and educates them better than any of the world's lower income countries" Baird (1993). Radical land reforms, female literacy and voluntary family planning enabled Kerala's people to achieve a quality of life 